\title{
Effects of Complex Heavy Metal Stress on the Hydrodynamic Parameters, Stem Anatomy and Photosynthetic Properties of Three Desert Species in the Jinchang Mining Area
}

\author{
Tian Peng Gao ( $\nabla$ zkgtp@163.com ) \\ Xi'an University \\ Hao Ming Wang \\ Lanzhou Jiaotong University \\ Changming $\mathrm{Li}$ \\ Lanzhou City College \\ Mingbo Zuo \\ Northwest Normal University \\ Xueying Wang \\ Institute of Environmental Health Science in Xi'an \\ Yuan Liu \\ Lanzhou Jiaotong University
}

Yingli Yang

Northwest Normal University

Yubing Liu

Lanzhou University

Guangqian Yao

Lanzhou University

Guohua Chang

Lanzhou City College

Danghui Xu

Lanzhou University

Xiangwen Fang

Lanzhou University

\section{Research Article}

Keywords: heavy metal stress, photosynthesis, hydraulic conductivity, stem anatomy

Posted Date: September 7th, 2021 
DOl: https://doi.org/10.21203/rs.3.rs-855904/v1

License: (c) (1) This work is licensed under a Creative Commons Attribution 4.0 International License. Read Full License 


\section{Abstract}

\section{Purpose}

The physiological mechanism and phytoremediation effects of heavy metal pollution by local desert plants, namely, Kochia scoparia, Chenopodium glaucum and Atriplex centralasiatica, around tailings were investigated.

\section{Methods}

Two different types of local soils (native soil and native soil + tailings, which are labeled CK and T, respectively) were used for potting experiments in the open, and the photosynthesis performance, chlorophyll content, hydraulics and stem anatomy of the potted plants were analyzed. The collection of soil samples has been approved by the soil resources management department of the local government.

\section{Results}

It was found that the chlorophyll content, photosynthetic rate and transpiration rate decreased but the chlorophyll a and b ( $\mathrm{Chl} \mathrm{a/b}$ ) and intercellular $\mathrm{CO}_{2}$ concentration (Ci) values increased in Kochia scoparia under complex heavy metal stress. Nonstomatal restriction led to a decrease in the net photosynthetic rate $(\mathrm{Pn})$ and damage to the chloroplasts. Additionally, four hydrodynamic parameters were elevated under heavy metal stress along with a decrease in duct density and diameter and a significant thickening of the duct wall. Under heavy metal stress, the changes in the chlorophyll parameters of Chenopodium glaucum, Atriplex centralasiatica and Kochia scoparia exhibited the same pattern, with stomatal restriction causing a decrease in $\mathrm{Pn}$ and $\mathrm{Ci}$ and a significant increase in the leaf specific conductance, hydraulic conductivity, and duct diameter.

\section{Conclusions}

Atriplex centralasiatica is the dominant desert plant in the region and demonstrates good adaptability and heavy metal accumulation under the stress of heavy metal tailings; therefore, it is a good candidate for tailings remediation in the Jinchang desert mining area.

\section{Background}

Heavy metal pollution caused by human activities has become a serious threat to terrestrial soil ecosystems [1]. One typical example is tailings pollution, which is the solid or liquid waste from mineral processing that is usually stored in open places without any protective measures. Tailings mostly contain the waste slag discharged by mining enterprises after the completion of mineral processing, which is often in the form of a slurry that can accumulate over time to form tailings ponds. Tailings ponds occupy a large area and are high safety hazards [2, 3]. Tailings contain large amounts of heavy metals such as lead, mercury, copper, nickel, and zinc that enter the soil and groundwater through rainfall, runoff, and 
wind, interfering with the ecosystem and threatening human life; therefore, the remediation of heavy metal-contaminated soil has become a global imperative $[4,5]$.

The most environmentally friendly and economical way to remediate mining sites is to treat contaminated land through bioremediation, which was first proposed by Chaney in 1983 to remove heavy metal contamination from soils using superenriched plants [6], followed by an increasing number of studies on plants tolerant to a low accumulation of heavy metals and superenriched plants. After phytoremediation was proposed as a technology to treat heavy metal-contaminated soils, engineering trials and field applications have shown that phytoremediation technology has great potential for commercialization. Phytoremediation can eliminate soil contaminants by immobilizing, extracting, and volatilizing heavy metals and exogenous compounds, and this technique can treat heavy metal contamination without damaging the soil environment [7, 8]. Desert plants of the families Gramineae, Chenopodiaceae, Asteraceae, and the genus Tribulus are relatively dominant species in the Jinchang mining area in northwestern China, Gansu Province, and are not limited by local climatic factors; thus, they may be used as candidate remediation plants. Moreover, Chenopodium plants have the ability to enrich heavy metals such as copper and nickel in large quantities and are more suitable for the remediation of heavy metal-contaminated waste sites [9].

The action of complex heavy metals on plants can cause complex effects. With respect to photosynthesis, abiotic stress-induced reductions in plant photosynthesis are usually caused mainly by stomatal restriction and nonstomatal restriction [10-14]. Under heavy metal stress, leaf water content is continuously reduced [15], and as the stomatal opening decreases, stomatal resistance increases and the amount of $\mathrm{CO}_{2}$ entering the stomata decreases; this results in a lower intercellular $\mathrm{CO}_{2}$ concentration (Ci) and leads to a lower photosynthetic rate in the plant $[16,17]$. Stomatal restriction at this stage is an important factor that decreases photosynthesis performance and is important for the study of photosynthesis by local plants in mining areas.

Regarding the indexes of plant hydraulics and their anatomical structure under abiotic stress, most of the studies in this area are on the changes in the hydraulic traits and anatomical structure parameters of cash crops under drought and salt stress [18-22]. In contrast, articles on heavy metal stress have focused on the determination and analysis of plant physiological indexes, and the changes in the plant hydraulics and anatomical structure have rarely been reported.

Therefore, the aim of this work is to analyze the photosynthetic response and the hydrodynamic and anatomical structure of three local species, namely, Kochia scoparia, Chenopodium glaucum, and Atriplex centralasiatica, under heavy metal stress from tailings to provide a theoretical basis for the selection of plants for tailings reclamation and in situ restoration.

\section{Methods}

\section{Soil type and planting conditions}


The soils used in the experiment consisted of native soil (from Xiasifen, 38 $39^{\circ} 16.23$ "N, $102^{\circ} 16^{\prime} 46.32$ "E) and slag tailings from direct operations (tailings dam $38^{\circ} 30^{\prime} 57.5$ "N, $102^{\circ} 09^{\prime} 4.2$ "E), and both the native soil and tailings samples were collected from the surface layer of the soil $(0-20 \mathrm{~cm})$; the experimental control group (virgin soil, CK) and an experimental group (virgin soil mixed with tailings at a ratio of $1: 1, T$ ) were prepared (Fig. 1). The whole experiment was conducted in the field experiment workstation at the center of pollution control and ecological restoration of the mining area in Gansu Province, which is $20 \mathrm{~km}$ away from the tailings dam in Jinchang City. In October 2018, the seeds of desert plants around the mining area were collected. After germination in the laboratory in March 2019, the seeds were planted in the field experiment workstation and managed by natural precipitation in open air.

The physicochemical properties of the soils are shown in Table 1, where the content of heavy metals in the virgin soil was lower than the Chinese national secondary standard (GB15618-2018), belonging to soil not contaminated by heavy metals. The cation exchange amounts of the two groups of soils were basically the same, and both were alkaline soils $(\mathrm{pH}>7)$.

The dominant plants were selected by survey markers in the mine area by the sample method. Three species of quinoa in good growth condition were identified, namely, Kochia scoparia, Chenopodium glaucum, and Atriplex centralasiatica, and their seeds were collected from uncontaminated areas near the mine area and planted in May 2019. The full and healthy seeds were selected and disinfected, rinsed three times with distilled water, scattered and planted into $60 \times 60 \mathrm{~cm}$ seedling pots in the field restoration base of the Jinchang mine and watered thoroughly. Three biological replicates were set up for each of the control and experimental groups, and various indicators were measured at the plant maturity stage after 110 days of incubation.

\section{Determination of the heavy metal content in the soil, physicochemical properties and heavy metal content inside the plants}

Five heavy metals, namely, copper (Cu), chromium ( $\mathrm{Cr}$ ), nickel (Ni), lead $(\mathrm{Pb})$ and zinc $(\mathrm{Zn})$, were identified in the blank group (native soil) and test group (tailings sand + native soil) soils by a flame atomic absorption spectrophotometer (TAS-990F Beijing Pu-Analysis General Instrument Co.). Among them, the soil cation exchange capacity (CEC) was determined by the sodium acetate method. The soil pH was measured with a pH meter (PHS-3E) (a water: soil ratio of 5:1). To study the relationship between the photosynthetic index and hydraulic index data and soil factors of the dominant local quinoa plants, the five heavy metals ( $\mathrm{Cr}, \mathrm{Ni}, \mathrm{Cu}, \mathrm{Pb}$ and $\mathrm{Zn}$ ) were determined in the three plants by the same method.

\section{Measurement of the photosynthetic parameters of plants}

The photosynthetic indexes of the upper and middle leaves of the plants were measured using a Li-6400 portable photosynthesizer with natural light from 9:00 to 11:00 a.m. every day as the light source during 
the maturation period, and three technical replicates were performed for each plant. The photosynthetic indexes measured were the net photosynthetic rate $\left(\mathrm{Pn}, \mathrm{CO}_{2}, \mu \mathrm{mol} \cdot \mathrm{m}^{-2} \cdot \mathrm{s}^{-1}\right)$, stomatal conductance (Gs, $\left.\mathrm{H}_{2} \mathrm{O}, \mathrm{mol} \cdot \mathrm{m}^{-2} \cdot \mathrm{s}^{-1}\right)$, transpiration rate $\left(\mathrm{Tr}, \mathrm{H}_{2} \mathrm{O}, \mathrm{mmol} \cdot \mathrm{m}^{-2} \cdot \mathrm{s}^{-1}\right)$ and intercellular $\mathrm{CO}_{2}$ concentration $(\mathrm{Ci}$, $\left.\mathrm{CO}_{2}, \mu \mathrm{mol} \cdot \mathrm{mol}^{-1}\right)$. After measuring the photosynthetic indexes, the middle and upper leaves of the plants were quickly collected and the chlorophyll content was measured by spectrophotometry at $663 \mathrm{~nm}$ and $665 \mathrm{~nm}$, respectively.

\section{Measurement of the plant hydraulic conductivity}

The hydraulic conductivity of the aboveground parts of the dominant plants was measured at the maturity stage of plant growth using a high-pressure hydraulic conductivity meter (HPFM-Gen3). Whole branches were measured at a distance of $3 \mathrm{~cm}$ from the soil surface and immediately placed in a bucket of water, covered with a black plastic bag (to prevent water loss and outside air from entering the branch through the incision) and brought to the laboratory for immediate measurement. The hydraulic

conductivity $\left(\mathrm{Kh}, \mathrm{kg} \cdot \mathrm{s}^{-1} \cdot \mathrm{MPa}^{-1}\right)$ was measured by cutting off underwater a 3-5 $\mathrm{cm}$ stem section near the branch incision before measurement (to reduce the effect of air entering the branch during sampling). The Specific hydraulic conductivity $\left(\mathrm{Ks}, \mathrm{kg} \cdot \mathrm{s}^{-1} \cdot \mathrm{MPa}^{-1} \cdot \mathrm{m}^{-2}\right)$ is the ratio of hydraulic conductivity to crosssectional area of wood, and the Leaf specific conductivity ( $\mathrm{LSC}, \mathrm{kg} \cdot \mathrm{s}^{-1} \cdot \mathrm{MPa}^{-1}$ ) can provide information of water supply for leaves in plants, and can be calculated from the formula: LSC = Kh / LA (LW). The Huber Value (HV) is defined as the stem cross-section area divided by the leaf area distal to the segment.

\section{Determination of the xylem anatomical parameters of the plant stems}

After measuring the hydraulic conductivity of the plant stems, the middle $3 \mathrm{~cm}$ of the stems were taken to study the anatomical structure study. The samples were sliced and washed thoroughly with distilled water. Next, a $0.5 \mathrm{~cm}$ section of the stem was cut, fixed with formalin-alcohol-acetic acid (FAA), and dehydrated in alcohol to make the xylem transparent. The xylem were immersed in wax and embedded in paraffin to make continuous paraffin sections before being double stained with red-solid green and sealed with neutral gum. Each sample was observed and photographed three times under an Olympus light microscope, and the anatomical structure of each part was measured by Cas Viewer.

\section{Results}

\section{Soil physiochemical properties and heavy metal content}

The cation exchange amounts of the soils at $0-20 \mathrm{~cm}$ were basically the same in both groups, and both were alkaline $(\mathrm{pH}>7)$. According to the Nemero pollution index algorithm, the comprehensive pollution index of the soil in the experimental group was calculated to be 29.54, which reached the heavy pollution level, and the contents of four heavy metals, namely, $\mathrm{Cr}, \mathrm{Cu}, \mathrm{Pb}$ and $\mathrm{Zn}$, exceeded the standard with 
concentrations of $1.25,11.41,11.91$ and 39.71 times those in the Chinese national secondary standard, respectively. The results are shown in Table 1.

Table 1

Soil physical and chemical property in soil $0-20 \mathrm{~cm}$ depth of two soil type

\begin{tabular}{|llllllll|}
\hline $\begin{array}{l}\text { Soil } \\
\text { type }\end{array}$ & $\mathrm{PH}$ & $\begin{array}{l}\text { Cation exchange } \\
\text { capacity }\end{array}$ & $\begin{array}{l}\mathrm{Cr} \\
(\mathbf{m g} / \mathbf{K g})\end{array}$ & $\begin{array}{l}\mathrm{Ni} \\
(\mathbf{m g} / \mathbf{K g})\end{array}$ & $\begin{array}{l}\mathrm{Cu} \\
(\mathbf{m g} / \mathbf{K g})\end{array}$ & $\begin{array}{l}\mathrm{Zn} \\
(\mathbf{m g} / \mathbf{K g})\end{array}$ & $\begin{array}{l}\mathrm{Pb} \\
(\mathbf{m g} / \mathbf{K g})\end{array}$ \\
\hline $\mathrm{CK}$ & 8.45 & 12.4 & 55.71 & 25.61 & 26.72 & 59.31 & 16.25 \\
\hline $\mathrm{T}$ & 8.23 & 6.86 & 312.05 & 114.02 & 1141.02 & 1113.01 & 2025.09 \\
\hline
\end{tabular}

The heavy metal contamination in the tailings mainly originate from three metals, namely, $\mathrm{Cu}, \mathrm{Zn}$ and $\mathrm{Pb}$, and the corresponding heavy metal contents in the three plants increased significantly after tailings stress. Atriplex centralasiatica had the highest enrichment content for $\mathrm{Zn}$, the highest enrichment coefficient for $\mathrm{Cu}$, and the highest transport coefficient for $\mathrm{Cr}$. The highest $\mathrm{Zn}$ content, the highest enrichment coefficient for $\mathrm{Ni}$ and the highest transport coefficient for $\mathrm{Cr}$ were found in Chenopodium glaucum. Kochia scoparia also had the highest $\mathrm{Zn}$ content, the highest enrichment coefficient for $\mathrm{Ni}$ and the highest transport coefficient for Cr; these results are shown in Fig. 2.

\section{Effect of heavy metals on plant photosynthesis}

The contents of chlorophyll $\mathrm{a}$ and $\mathrm{b}$ in the plants showed significant decreases under complex heavy metal stress (Fig. 3E and F). The Chl a/b values of Atriplex centralasiatica and Chenopodium glaucum showed significant increases after stress, while the $\mathrm{Chl}$ a/b values of Kochia scoparia slightly decreased, but not significantly (Fig. $3 \mathrm{H}$ ). Under complex heavy metal stress, photosynthetic rate differences were significant in all three plants, and the photosynthetic rate decreased after stress; however, the photosynthetic rate of Atriplex centralasiatica was significantly higher than the other two plants (Fig. 3A). Under complex heavy metal stress, Kochia scoparia showed an increase in its intercellular $\mathrm{CO}_{2}$ concentration (Ci value), while Chenopodium glaucum and Atriplex centralasiatica showed a decrease in their $\mathrm{Ci}$ values. Notably, the Ci values of Kochia scoparia and Chenopodium glaucum were significantly higher than that of Atriplex centralasiatica, with Chenopodium glaucum having the highest Ci value (Fig. 3B). The transpiration rate and stomatal conductance of all three plants showed a significant decrease under complex heavy metal stress, with Chenopodium glaucum having the highest stomatal conductance, followed by Atriplex centralasiatica and Kochia scoparia (Fig. 3C). Atriplex centralasiatica had a greater transpiration rate than Chenopodium glaucum, and Kochia scoparia had the smallest transpiration rate (Fig. 3D).

\section{Effect of heavy metals on plant hydraulics}


Under complex heavy metal stress, Atriplex centralasiatica had the highest hydraulic conductivity, followed by Kochia scoparia and Chenopodium glaucum (Fig. 4A). The leaf specific conductance was the highest in Atriplex centralasiatica, followed by Kochia scoparia and Chenopodium glaucum (Fig. 4B), indicating that Atriplex centralasiatica had the best water supply per unit leaf area after stress. The water supply per unit leaf area was the best after stress, showing that water was still available. Atriplex centralasiatica had the largest Huber value and it was significantly higher than the other two plants (Fig. 4D), reflecting that Atriplex centralasiatica had the most well-maintained water supply per unit leaf area because the stem tissue required to maintain the water supply per unit leaf area of Atriplex centralasiatica was the largest.

The specific conductance (Ks) of the Atriplex centralasiatica xylem was significantly higher than that of the other two plants (Fig. 4C). Therefore, Atriplex centralasiatica had a strongest water transport capacity per unit effective area than the other two plants.

\section{Effect of heavy metals on the anatomical structure of plant stems}

The morphology and distribution characteristics of plant sapwood ducts vary by plant species (Appendix Fig. 1) and largely determine the sapwood hydraulic conductivity and water transport regulation, which are important anatomical features that determine plant water consumption.

After heavy metal stress, Atriplex centralasiatica and Chenopodium glaucum both showed a significant increase in their conduit diameters, and Kochia scoparia showed a significant decrease (Fig. 5A). Additionally, the relative thinning area and conduit density of all three sapwood species showed a significant decrease (Fig. 5B and C). The relative conductance area refers to the ratio of the cumulative cross-sectional area of sapwood conduits to the sapwood area, which is an important index for evaluating the water transfer efficiency of forest trees. The proportion of sapwood cross-sectional water transport tissue varies greatly among species with different conduit distribution types. Especially when trees are in near-potential transpiration, the size of the transport area can directly reflect the water consumption of trees.

Under heavy metal stress, we found that the heavy metal stress induced thicker duct walls after analyzing the duct wall thickness of studied plants. The average duct wall thickness of Atriplex centralasiatica after stress was significantly higher than that of the other two plants (Fig. 5D and Fig. 6).

\section{Correlation analysis}

Correlation analysis of the transpiration, hydraulics and anatomical parameters showed that the transpiration rate and stomatal conductance of Kochia scoparia were significantly and positively correlated with the leaf specific conductance and stem hydraulic conductance after heavy metal stress. Moreover, the stem hydraulic conductance and leaf specific conductance were positively correlated with the duct diameter and duct wall thickness. Finally, the duct wall thickness was positively correlated with 
heavy metal content in the stem, while the heavy metal content in the plant leaves and the transpiration rate were positively correlated (Fig. 7A).

Chenopodium glaucum showed changes in the correlation of physiological indicators after heavy metal stress (Fig. 7B), the heavy metal content in leaves and leaf specific conductance were significantly and positively correlated, the stomatal conductance and stem hydraulic conductance were significantly and positively correlated, and the heavy metal content in the stem was positively correlated with the duct wall thickness, hydraulic conductance, and stomatal conductance.

Atriplex centralasiatica also showed significant differences in correlation after heavy metal stress (Fig. 7C), the transpiration rate and leaf specific conductance were significantly and positively correlated, the leaf specific conductance was positively correlated with the heavy metal content in leaves, and the heavy metal content in the stem was significantly and positively correlated with the duct wall thickness.

\section{Discussion}

The chlorophyll content is an important parameter for the determination of photosynthesis in plants and is involved in the absorption, transfer and conversion of light energy during photosynthesis. Chlorophyll plays a key role in photosynthesis, and changes in its content reflect the degree of photosynthesis that occurs [23]. The central atom of chlorophyll, magnesium, can be replaced by heavy metals such as cadmium, copper, zinc, lead and mercury, hampering the light-harvesting ability of chlorophyll and impairing photosynthesis performance in stressed plants [24]; furthermore, the chlorophyll in plants under heavy metal stress is subject to metabolic disruption and inhibited synthesis [25,26]. $\mathrm{Zn}$ is an essential element for plant growth, and when the $\mathrm{Zn}$ concentration exceeds a critical value, large amounts of $\mathrm{Zn}$ enter chlorophyll cells and disrupt chlorophyll metabolism and chlorophyllase activity, leading to a decreased synthesis of chlorophyll. In this paper, the three studied plants showed a decrease in their chlorophyll $A$ and $B$ contents under heavy metal stress from tailings, while the chlorophyll A/B ratio reflected the relative ratio of stacked to unstacked membrane domains and was inversely proportional to the degree of cystoid compression. Cystoid compression is responsible for bringing the light-trapping chlorophyll protein complex (LHCII) closer together, making it useful for maximizing the light-harvesting capacity. Additionally, the PSII reaction center in the stacked region is in the same pigment bed as the adjacent LHCII, which further increases the energy transfer capacity of the membrane [27].The increase in the chlorophyll A/B ratio after heavy metal stress is assumed to be due to the cystoid not being stressed, and the reduction in the cystoid is a positive sign of plant adaptation to environmental stress [28].

Photosynthesis is an important indicator to evaluate plant growth and development and plant productivity. Stomata are important structures in plant leaves that control photosynthesis, $\mathrm{CO}_{2}$ and water uptake and transpiration; thus, the physiological indicators of stomata have an important influence on the photosynthetic physiology of plants. In general, stomatal factors mainly include the number, size and opening of stomata, while nonstomatal factors include enzyme activity and the photosynthetic components. Under environmental stress, both stomatal and nonstomatal limitations lead to a decrease 
in $\mathrm{Pn}$, but $\mathrm{Ci}$ is used to distinguish between stomatal and nonstomatal limitations [29]. When both Pn and $\mathrm{Ci}$ are reduced, the decrease in photosynthetic capacity is caused by stomatal limitation; however, when the photosynthetic rate decreases and $\mathrm{Ci}$ increases, the cause is nonstomatal limitation [30]. In this paper, Kochia scoparia under heavy metal stress showed a significant decrease in Pn, Gs, and a significant increase in $\mathrm{Ci}$, compared to the control group, indicating that under heavy metal stress, the Kochia scoparia leaf Pn decreased mainly due to nonstomatal limiting factors. In contrast, under heavy metal stress, Chenopodium glaucum and Atriplex centralasiatica showed a significant decrease in Pn, Gs, and Ci compared to the control group, indicating that the photosynthetic rate of these two plants decreased due to stomatal limiting factors. All three plants showed a significant decrease in transpiration rate after heavy metal stress, and the order of decrease was: Atriplex centralasiatica > Chenopodium glaucum > Kochia scoparia.

Studies on the relationship between the stomatal regulation, leaf transpiration rate and heavy metal accumulation in the plants are now well documented [31, 32], and heavy metal accumulation in the aboveground parts of the plants is subject to several processes, including root uptake, radial transport, xylem loading and transport from roots to the aboveground parts. Transpiration is the driving force for a large amount of water flow in this process. Therefore, the heavy metal content of the aboveground part of the plant, is thought to be achieved due to the entire flow transport mechanism from the soil substrate to the stem and then to the leaves through transpiration [33]; this flow of heavy metals is enhanced when the stomatal conductance increases, which increases the flux of water-soluble pollutants to the upper part of the plant. It was hypothesized that plants with more efficient water use and fast stomatal response were more desirable target candidates for tailings remediation. The transpiration rate and hydraulic conductivity of Atriplex centralasiatica were significantly higher than those of the other two plants, and its duct diameter was also larger than those of the other plants. Therefore, Atriplex centralasiatica had the highest heavy metal content among the three plants.

There are two factors influencing the hydraulic conductivity of plants: the intrinsic factors of plants, including the hydraulic structure, morphological structure and osmotic potential of plants; and the extrinsic factors, including soil factors such as the water status, nutrient conditions, salt content, temperature, and atmospheric factors such as the available light, $\mathrm{CO}_{2}$ concentration, and solar radiation. Usually, exogenous factors cause changes in endogenous factors [34]. Plants can regulate the hydraulic properties of xylem under different stress conditions and can maintain a high hydraulic efficiency of stems and roots by reducing the root hydraulic conductivity [35]. Maggio et al. (1995) revealed that heavy metals play a strong inhibitory role on the hydraulic conductivity of tomato roots, and their study showed that the root hydraulic conductivity significantly reduced by $57 \%$ during heavy metal ion treatment [36].

This study discussed the changes in plant stem hydraulics indicators under heavy metal stress, and it was found that all four hydraulics indicators of the three plants showed a significant increase under heavy metal stress, thereby leading to a higher leaf specific conductance. These results are consistent with the results of Adriana M's study on the regulation of the plant response under copper stress, which found an increase in the leaf specific conductance of plants under heavy metal copper stress [37]. The 
present study showed that the hydraulic conductivity and leaf specific conductance were significantly higher in the three studied plants grown under long-term heavy metal stress than in those grown in the native desert (Fig. 4).

Most of the current studies on plant stem anatomy are on drought and salinity stress, and rarely involve heavy metal stress, but there are studies on the enrichment of heavy metals by non-hyperenriched plants. For example, plants can chelate heavy metals through substances such as polysaccharides in the cell wall [38], and the cell wall thickness of mosses can be increased by inducing organizational changes of the cell wall polysaccharides and cell wall structural morphology [39].

In the present study, we found that the duct density and relative sparing area of all three plants under complex heavy metal stress showed a significant decrease compared to the control, while the xylem duct wall showed a trend of thickening. These results were similar to Krzesowska et al., who previously found that the cell wall pectin chelates with heavy metals entering the cell wall, resulting in an increase in cell wall thickness and hardness [40]. This study showed that the duct wall thickness of desert plants was significantly higher than that of the unstressed group after being subjected to long-term heavy metal stress, and the duct wall thickness after stress was positively correlated with the heavy metal content in the stem. Hajihashemi et al. (2020) found that the ductal density of wheat roots decreased during heavy metal effluent treatment [41], and the same trend was found in the stems of our study, which showed that the ductal density of plants under stress was significantly lower than that of the unstressed group.

This increase in duct diameter is consistent with the findings of Adriana et al. (2016), in which purple willow (Salix purpurea $L$.) showed an increase in its xylem duct diameter after stress by copper ions and other heavy metals [37]. Accordingly, we hypothesize that transpiration is not the only factor that promotes the increase in plant hydraulic conductivity because the stem hydraulic conductivity from the underground to the aboveground parts of plants can be maintained by increasing the vascular diameter when under stress.

\section{Conclusion}

Under complex heavy metal stress, the chlorophyll content, photosynthetic rate, and transpiration rate of Kochia scoparia decreased, but the $\mathrm{Chl} \mathrm{a/b}$ and Ci values increased. Nonstomatal restriction led to a decrease in $\mathrm{Pn}$ and damage to the chloroplasts. Additionally, the hydraulics parameters increased, the duct density and diameter decreased, and the duct wall significantly thickened. The pattern of changes in the chlorophyll parameters of Chenopodium glaucum, Atriplex centralasiatica and Kochia scoparia was consistent. Atriplex centralasiatica was significantly higher than the other two desert plants in all indexes, with better adaptability and heavy metal accumulation under heavy metal stress from tailings. Atriplex centralasiatica is the dominant desert plant in the area and is easy to maintain; thus, it is a good candidate for tailings remediation in the Jinchang desert mining area.

\section{Abbreviations}


Chl a: chlorophyll a; Chl b: chlorophyll b; Ci: intercellular CO2 concentration

Pn: net photosynthetic rate; Gs: stomatal conductance; E: transpiration rate

Kh: hydraulic conductivity; Ks: Specific hydraulic conductivity; HV: Huber Value

LSC: Leaf specific conductivity; LMC: Leaf metal content; SMC: stem metal content

VD: Vessel diameter; CWT: Cell wall thinkness

\section{Declarations}

\section{Ethics approval and consent to participate}

Not applicable

Consent for publication

Not applicable

\section{Availability of data and materials}

The datasets used and/or analyzed during the current study are available from the corresponding author on reasonable request.

\section{Competing interests}

The authors declare that they have no conflict of interest.

\section{Funding}

This work was financially supported by the National Natural Science Foundation of China (NSFC 31860176, 32171611, 32160749, 41977204), Key Research and Development Program of Gansu (20YF3FA037, 20YF3FA043), Key Research and Development Program of Shanxi (2020ZDLSF06-06) and XAWLKYTD012. We are grateful to all anonymous reviewers whose comments improved the quality of the manuscript.

\section{Authors' contributions}

We would like to thank Y. L., H.M.W., M.B.Z., X.Y.W., G.Q.Y., and C.M.L., they carried out the experiments. Y.L.Y., D.H.X., and G.H.C. designed the experiments and analyzed the data. T.P.G., Y.B.L., and X.W.F. wrote and edited the manuscript.

\section{Acknowledgements}


We are very grateful to all the staff of Jinchang workstation, Liu Yongxian, the general manager of Bayi state farm of Agricultural Reclamation Co., Ltd of Gansu (BARG), Wei Hongjun, the stationmaster of the experimental station, Wan Zidong, Fu Jingwen, Jin Xingang, Wang Jia, Zhang Yanxin, Wang Zhi and other students, and the canteen staff of Tianshengkang branch of BARG for their sincerely help to our research team.

\section{References}

1. Jaya Mary Jacob, Chinnannan Karthik, Rijuta Ganesh Saratale, Smita S. Kumar, Desika Prabakar, K. Kadirvelu, Arivalagan Pugazhendhi. Biological approaches to tackle heavy metal pollution: A survey of literature. Journal of Environmental Management. 2018;217:56-70.

2. Uchenna Okereafor, Mamookho Makhatha, Lukhanyo Mekuto, Nkemdinma Uche-Okereafor, Tendani Sebola, Vuyo Mavumengwana. Toxic Metal Implications on Agricultural Soils, Plants, Animals, Aquatic life and Human Health. International Journal of Environmental Research and Public Health. 2020;17:2204. https://doi.org/10.3390/ijerph17072204

3. Kumar Adarsh, Tripti, Maleva Maria, Kiseleva Irina, Maiti Subodh Kumar, Morozova Maria. Toxic metal(loid)s contamination and potential human health risk assessment in the vicinity of century-old copper smelter, Karabash, Russia. Environmental geochemistry and health. 2020;42:4113-4124.

4. Zhenli L. He, Xiaoe E. Yang, Peter J. Stoffella. Trace elements in agroecosystems and impacts on the environment. Journal of Trace Elements in Medicine and Biology. 2005;19:125-140.

5. Ellen Sträter, Anna Westbeld, Otto Klemm. Pollution in coastal fog at Alto Patache, Northern Chile. Environmental Science and Pollution Research. 2010;17:1563-1573.

6. Chaney R L, Mli Y M, Brown S L, et al. Phytoremediation of Soil Metals. Current Opinion in Biotechnology. 1997;8:279-284.

7. Bernard R. Glick. Using soil bacteria to facilitate phytoremediation. Biotechnology Advances. 2010;28:367-374.

8. Dahmani-Muller, F Van Oort, B Gélie, M Balabane. Strategies of heavy metal uptake by three plant species growing near a metal smelter. Environmental Pollution. 2000;109:231-238.

9. Gao Tian Peng, Wan Zi Dong, Liu Xiao Xiao, Fu Jing Wen, Chang Guo Hua, Sun Hai Li, Li Hai Juan, Shen Yuan Yuan, Liu Yu Bing, Fang Xiang Wen. Effects of heavy metals on bacterial community structure in the rhizosphere of; and bulk soil in the Jinchuan mining area. Geomicrobiology Journal. 2021;38:1-11.

10. Behrooz Sarabi, Chantal Fresneau, Nasser Ghaderi, Sahebali Bolandnazar, Peter Streb, Franz-Werner Badeck, Sylvie Citerne, Maëva Tangama, Andoniaina David, Jaleh Ghashghaie. Stomatal and nonstomatal limitations are responsible in down-regulation of photosynthesis in melon plants grown under the saline condition: Application of carbon isotope discrimination as a reliable proxy. Plant Physiology and Biochemistry. 2019;141:1-19. 
11. Marion Eisenhut, Andrea Bräutigam, Stefan Timm, Alexandra Florian, Takayuki Tohge, Alisdair R. Fernie, Hermann Bauwe, Andreas P.M. Weber. Photorespiration Is Crucial for Dynamic Response of Photosynthetic Metabolism and Stomatal Movement to Altered $\mathrm{CO}_{2}$ Availability. Molecular Plant. 2017;10:47-61.

12. Zhang S Y, Zhang G C, Gu S Y, et al. Critical responses of photosynthetic efficiency of goldspur apple tree to soil water variation in semiarid loess hilly area. Photosynthetica. 2010;48:589-595.

13. Xingyang Song, Guangsheng Zhou, Qijing He,Huailin Zhou. Stomatal limitations to photosynthesis and their critical Water conditions in different growth stages of maize under water stress. Agricultural Water Management. 2020;241:106330. DOI: 10.1016/j.agwat.2020.106330

14. Qiulong Yin, Tingting Tian, Meng Kou, Peiliang Liu, Lei Wang, Zhanqing Hao, Ming Yue. The relationships between photosynthesis and stomatal traits on the Loess Plateau. Global Ecology and Conservation. 2020;23:e01146. https://doi.org/10.1016/j.gecco.2020.e01146

15. Xiao Mengting, Cui Xuemei, Nie Haojie, Zhang Wenjiao. Effects of heavy metal chromium stress on rape growth and chromium accumulation.Journal of Hubei Institute of Technology. 2020;40:24-27.

16. Cai Yanfei, Wang Jihua, Li Shifeng, Zhang Lu, Peng Lvchun, Xie Weijia, Liu Feihu. Photosynthetic Response of an Alpine Plant, Rhododendron delavayi Franch, to Water Stress and Recovery: The Role of Mesophyll Conductance. Frontiers in Plant Science. 2015;365: 2707-2719.

17. Yuping Li, Hongbing Li, Yuanyuan Li, Suiqi Zhang. Improving water-use efficiency by decreasing stomatal conductance and transpiration rate to maintain higher ear photosynthetic rate in droughtresistant wheat. The Crop Journal. 2017;5:231-239.

18. Rodrigo T. Avila, Amanda A. Cardoso, Wellington L. de Almeida, Lucas C. Costa, Kleiton L.G. Machado, Marcela L. Barbosa, Raylla P.B. de Souza, Leonardo A. Oliveira, Diego S. Batista, Samuel C.V. Martins, José D.C. Ramalho, Fábio M. DaMatta. Coffee plants respond to drought and elevated $\left[\mathrm{CO}_{2}\right]$ through changes in stomatal function, plant hydraulic conductance, and aquaporin expression. Environmental and Experimental Botany. 2020;177:104148.

https://doi.org/10.1016/j.envexpbot.2020.104148

19. Gabriela Quiroga, Gorka Erice, Ricardo Aroca, Ángel María Zamarreño, José María García-Mina, Juan Manuel Ruiz-Lozano. Radial water transport in arbuscular mycorrhizal maize plants under drought stress conditions is affected by indole-acetic acid (IAA) application. Journal of Plant Physiology. 2020;246-247:153115 https://doi.org/10.1016/j.jplph.2020.153115

20. Machado Filho José Altino, Rodrigues Weverton Pereira, Baroni Danilo Força, Pireda Saulo, Campbell Glaziele, de Souza Guilherme Augusto Rodrigues, Verdin Filho Abraão Carlos, Arantes Sara Dousseau, de Oliveira Arantes Lúcio, da Cunha Maura, Gambetta Gregory A, Rakocevic Miroslava, Ramalho José Cochicho, Campostrini Eliemar. Linking root and stem hydraulic traits to leaf physiological parameters in Coffea canephora clones with contrasting drought tolerance. Journal of plant physiology. 2021;258-259:153355. https://doi.org/10.1016/j.jplph.2020.153355

21. Rajput V D, Minkina T, Yaning $C$, et al. A review on salinity adaptation mechanism and characteristics of Populus euphratica, a boon for arid ecosystems. Acta Ecologica Sinica. 2016;36:497-503. 
22. Win K T, Oo A Z, Ookawa T, et al. Changes in hydraulic conductance cause the difference in growth response to short-term salt stress between salt-tolerant and -sensitive black gram (Vigna mungo) varieties. Journal of Plant Physiology. 2016;193:71-78.

23. Yaoling Zhang, Jinzhou Du, Fenfen Zhang. Chemical characterization of humic substances isolated from mangrove swamp sediments: The Qinglan area of Hainan Island, China. Estuarine, Coastal and Shelf Science. 2011;92:180-187

24. Hendrik Küpper, Frithjof Küpper, Martin Spiller. Environmental relevance of heavy metal-substituted chlorophylls using the example of water plants. Journal of Experimental Botany. 1996;47:259-266.

25. Zhang H, Xu Z, Guo K, et al. Toxic effects of heavy metal Cd and Zn on chlorophyll, carotenoid metabolism and photosynthetic function in tobacco leaves revealed by physiological and proteomics analysis. Ecotoxicology and Environmental Safety. 2020;202:110856.

https://doi.org/10.1016/j.ecoenv.2020.110856

26. Zeeshan M. Phytostabalization of the heavy metals in the soil with biochar applications, the impact on chlorophyll, carotene, soil fertility and tomato crop yield. Journal of Cleaner Production. 2020,255:120318. https://doi.org/10.1016/j.jclepro.2020.120318

27. Anderson J M, Aro E M. Grana stacking and protection of Photosystem II in thylakoid membranes of higher plant leaves under sustained high irradiance: An hypothesis. Photosynthesis Research. 1994;41:315-326.

28. Wang Y, Jiang X, Li K, et al. Photosynthetic responses of Oryza sativa L. seedlings to cadmium stress: physiological, biochemical and ultrastructural analyses. Biology of Metals. 2014;27:389-401.

29. Farquhar G D, Sharkey T D. Stomatal Conductance and Photosynthesis. Annual Review of Plant Physiology. 1982;33:317-345.

30. Ainsworth E A, Rogers A. The response of photosynthesis and stomatal conductance to rising $\left[\mathrm{CO}_{2}\right]$ : mechanisms and environmental interactions. Plant Cell \& Environment, 2010, 30:258-270.

31. Liu X, Peng K, Wang A, et al. Cadmium accumulation and distribution in populations of Phytolacca americana L. and the role of transpiration. Chemosphere. 2010;78:1136-1141.

32. Liu H, Wang $\mathrm{H}, \mathrm{Ma}$ Y, et al. Role of transpiration and metabolism in translocation and accumulation of cadmium in tobacco plants (Nicotiana tabacum L.). Chemosphere. 2016;144(FEB.):1960-1965.

33. Salt D E, Prince R C, Raskin P I. Mechanisms of Cadmium Mobility and Accumulation in Indian Mustard. Plant Physiology. 1995;109:1427-1433.

34. Yang Qiliang, Zhang Fucang, Liu Xiaogang, Zhang Nan, Ge Zhenyang. Research progress in plant hydraulic conductance under different environmental factors. Chinese Journal of Eco-Agriculture. 2011;19: 456-461.

35. Rajput V D, Minkina T, Yaning C, et al. A review on salinity adaptation mechanism and characteristics of Populus euphratica, a boon for arid ecosystems. Acta Ecologica Sinica. 2016;36:497-503.

36. Maggio A, Joly R J. Effect of mercuric chloride on the hydraulic conductivity of tomato root system. Plant Physiology. 1995;109: 331-335. 
37. Almeida-Rodríguez Adriana M, Gómes Marcelo P, Loubert-Hudon Audrey, Joly Simon, Labrecque Michel. Symbiotic association between Salix purpurea L. and Rhizophagus irregularis. modulation of plant responses under copper stress. Tree physiology. 2016;36:407-420.

38. Konno H ,Nakashima S, Katoh K. Metal-tolerant moss Scopelophila cataractae accumulates copper in the cell wall pectin of the protonema. Journal of Plant Physiology. 2010;167:358-364.

39. Krzesłowska M, Lenartowska M, Mellerowicz E J, et al. Pectinous cell wall thickenings formation-A response of moss protonemata cells to lead. Environmental \& Experimental Botany. 2009;65:119131.

40. Hajihashemi S, Mbarki S, Skalick Y M , et al. Effect of Wastewater Irrigation on Photosynthesis, Growth, and Anatomical Features of Two Wheat Cultivars (Triticum aestivum L.). Water. 2020;12:607.

41. Becker Peter,Tyree Melvin T.,Tsuda Makoto. Hydraulic conductances of angiosperms versus conifers: similar transport sufficiency at the whole-plant level. Tree physiology. 1999;19: 445-452.

42. Ganthaler A, Katharina $M$, Beikircher B, et al. Are hydraulic patterns of lianas different from trees? New insights from Hedera helix. Journal of Experimental Botany. 2019;70(10):2811-2822.

\section{Figures}




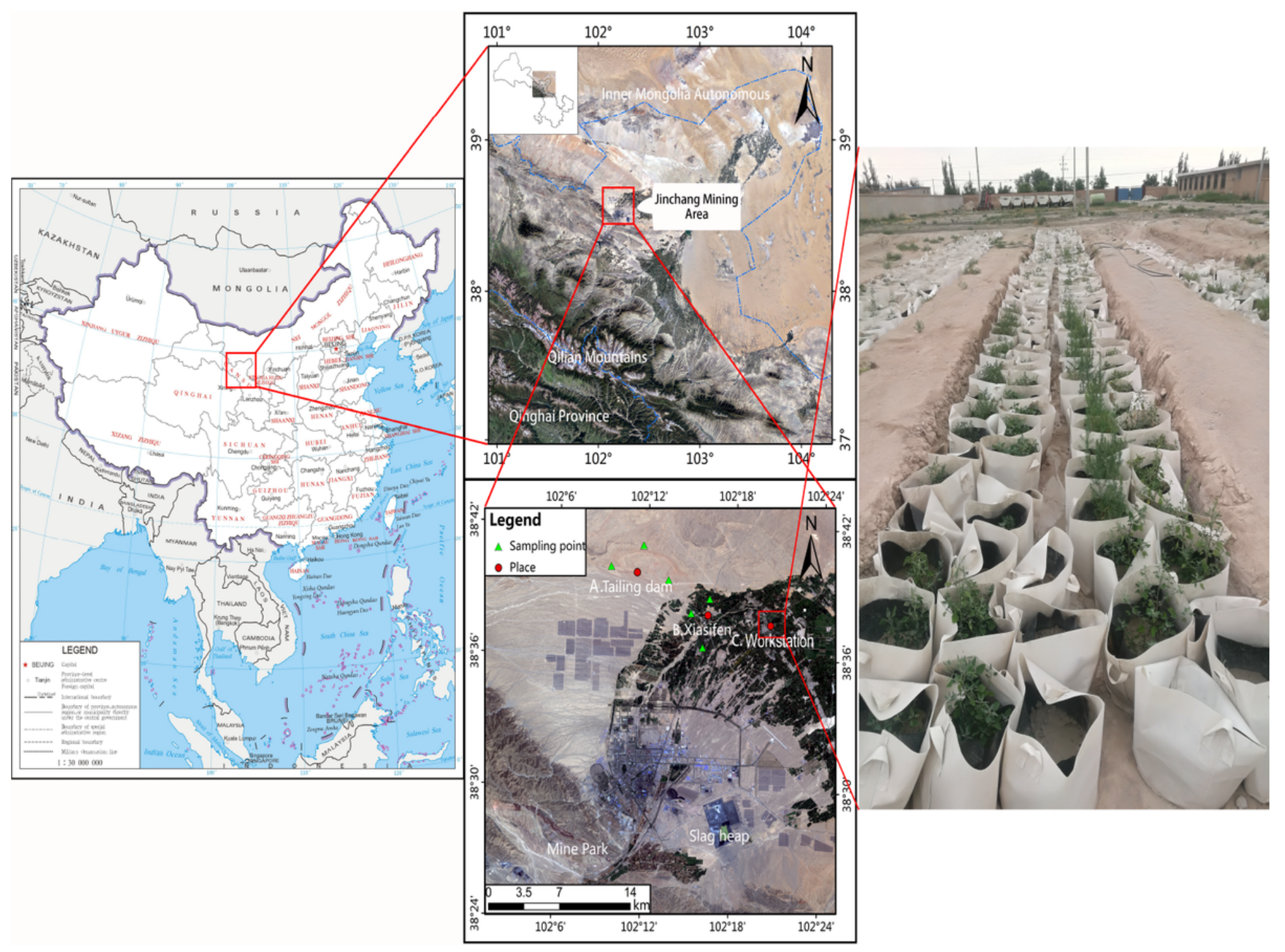

Figure 1

Site selection of sample sites in the study area (Gansu Province, China). 

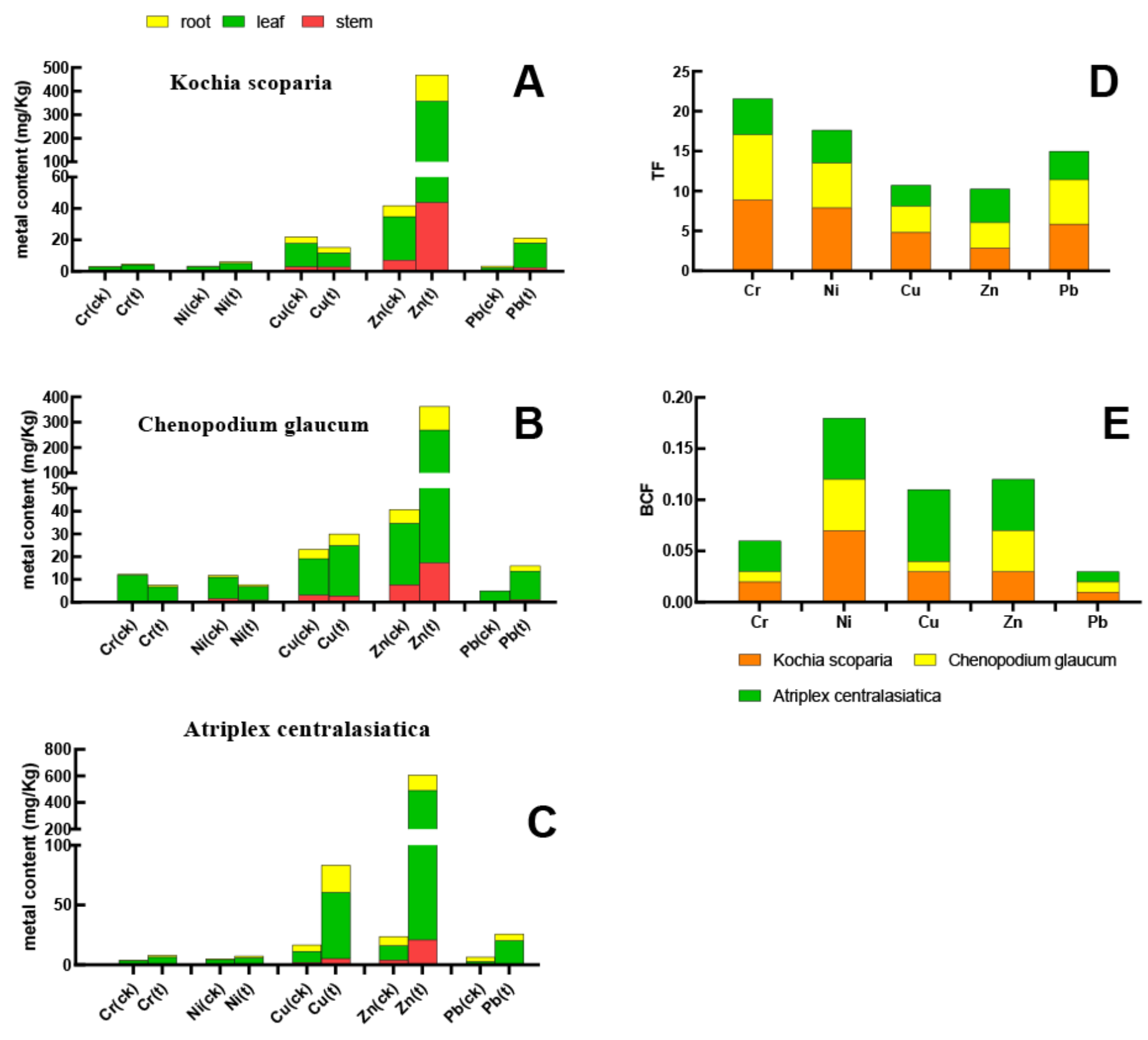

Figure 2

$A, B$, and $C$ show the heavy metal content of each part of the plant. D and $E$ show the plant enrichment and transport coefficients, respectively. 

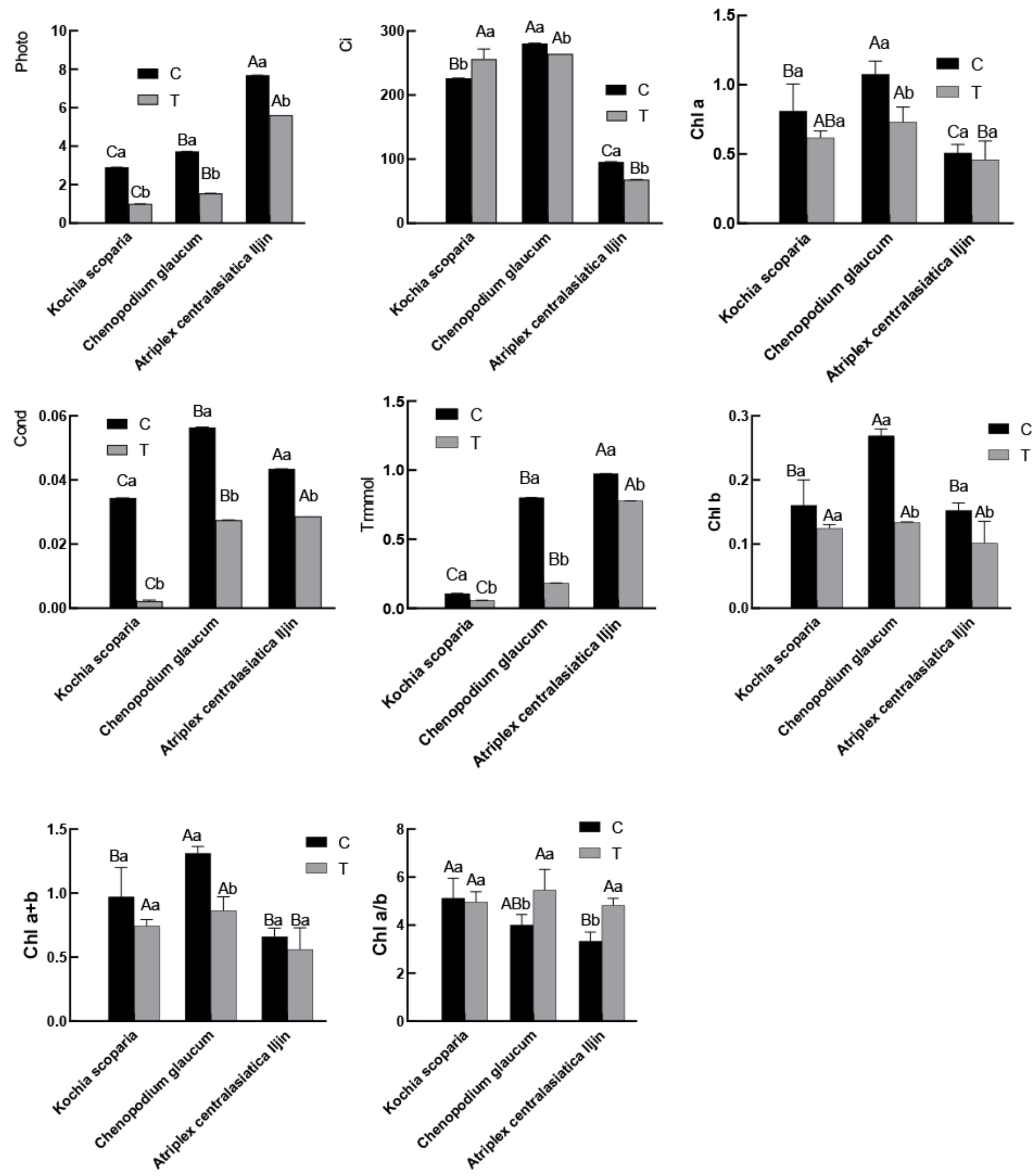

\section{Figure 3}

Changes in chlorophyll content of plants under heavy metal stress. The different lowercase letters indicate significant differences between processing, while the different capital letters indicate significant differences between plants $(P<0.05)$. 

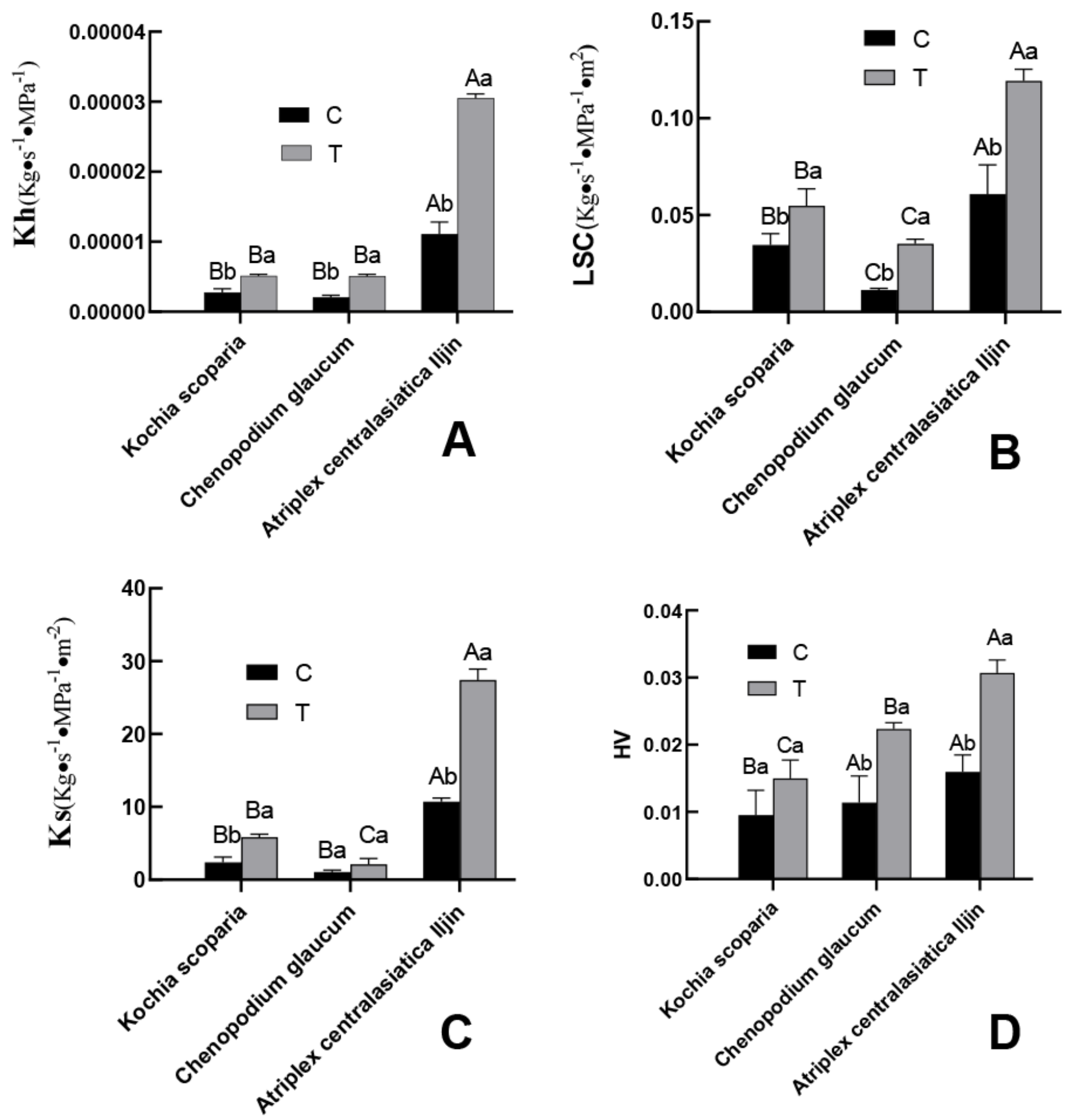

Figure 4

Effect of complex heavy metal stress on plant hydraulic conductance. The different lowercase letters indicate significant differences between treatments, while the different uppercase letters indicate significant differences between plants $(P<0.05)$. 

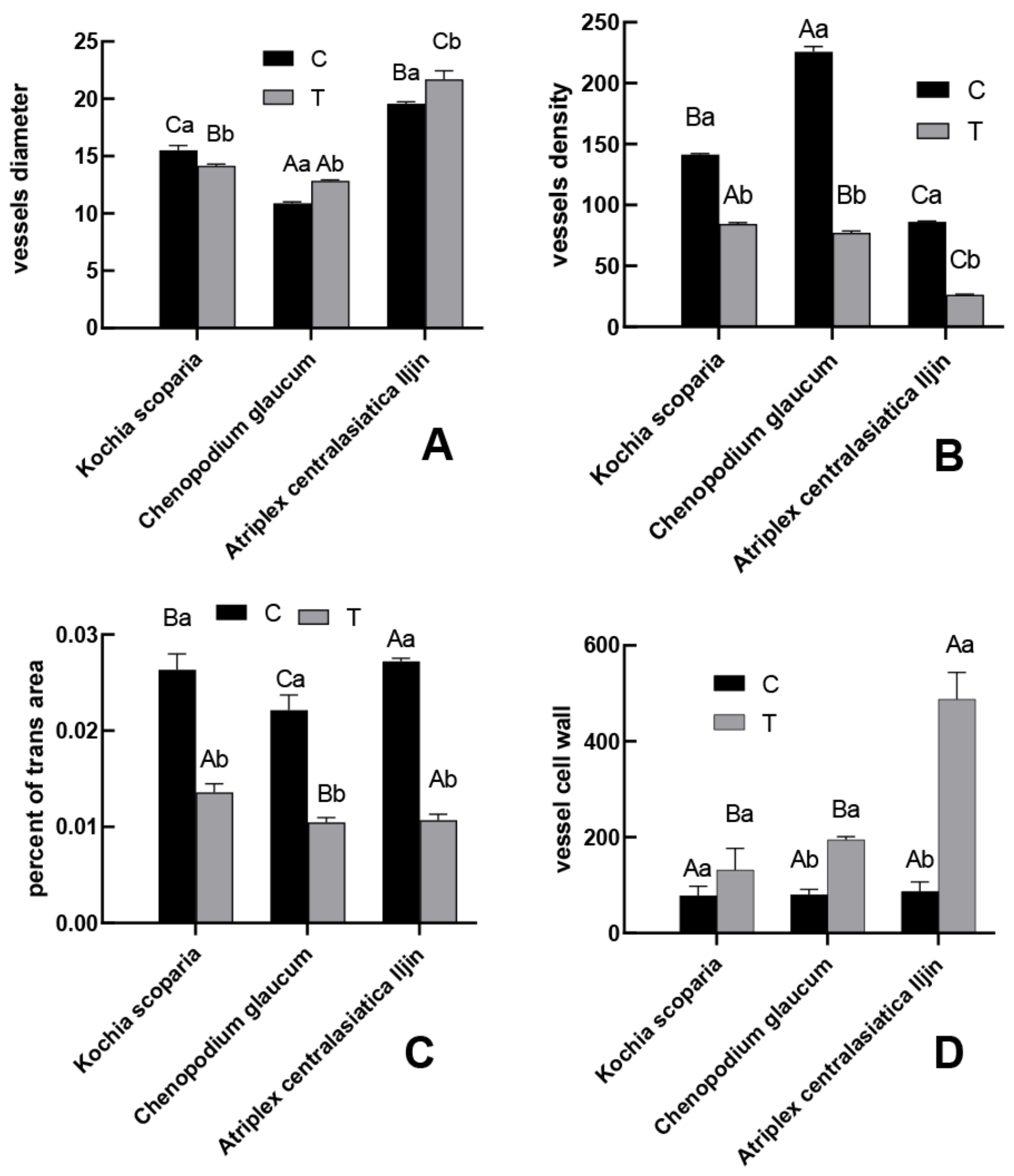

Figure 5

Effect of heavy metal stress on the anatomical structure of the plant stems. The different lowercase letters indicate significant differences between treatments, while the different capital letters indicate significant differences between plants $(P<0.05)$. 


\section{Kochia scoparia}

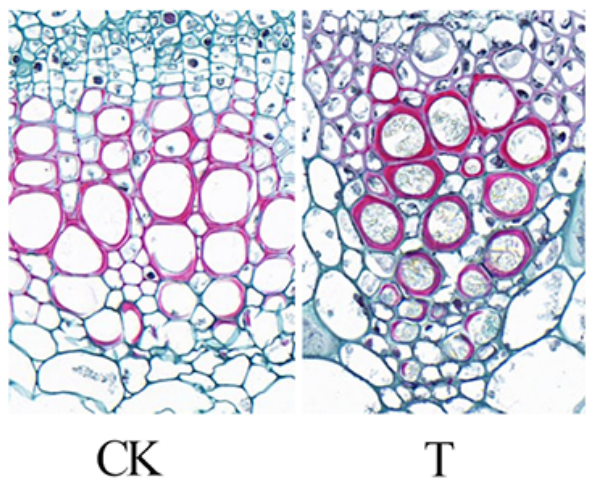

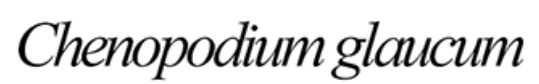

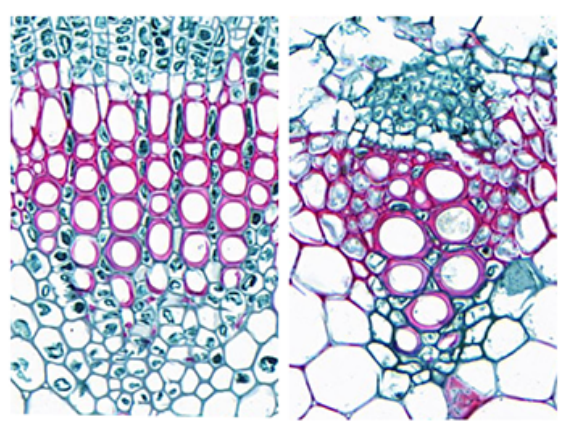

CK

\section{Atriplex centralasiatica Iljiin}

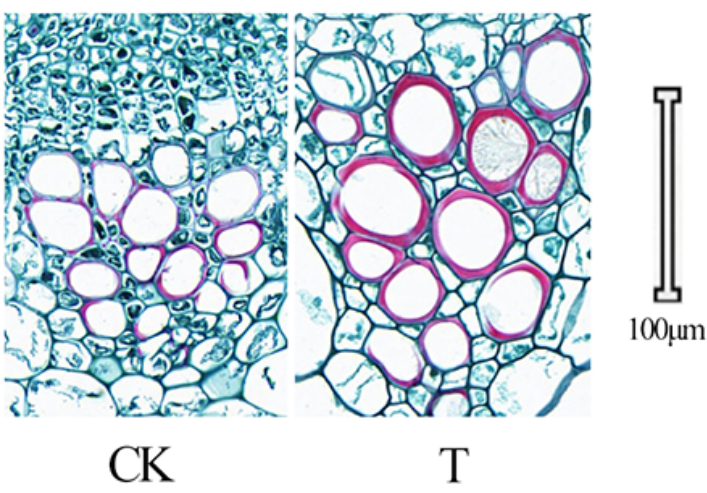

Figure 6

Comparison of the vascular bundle slices of the plant stems.
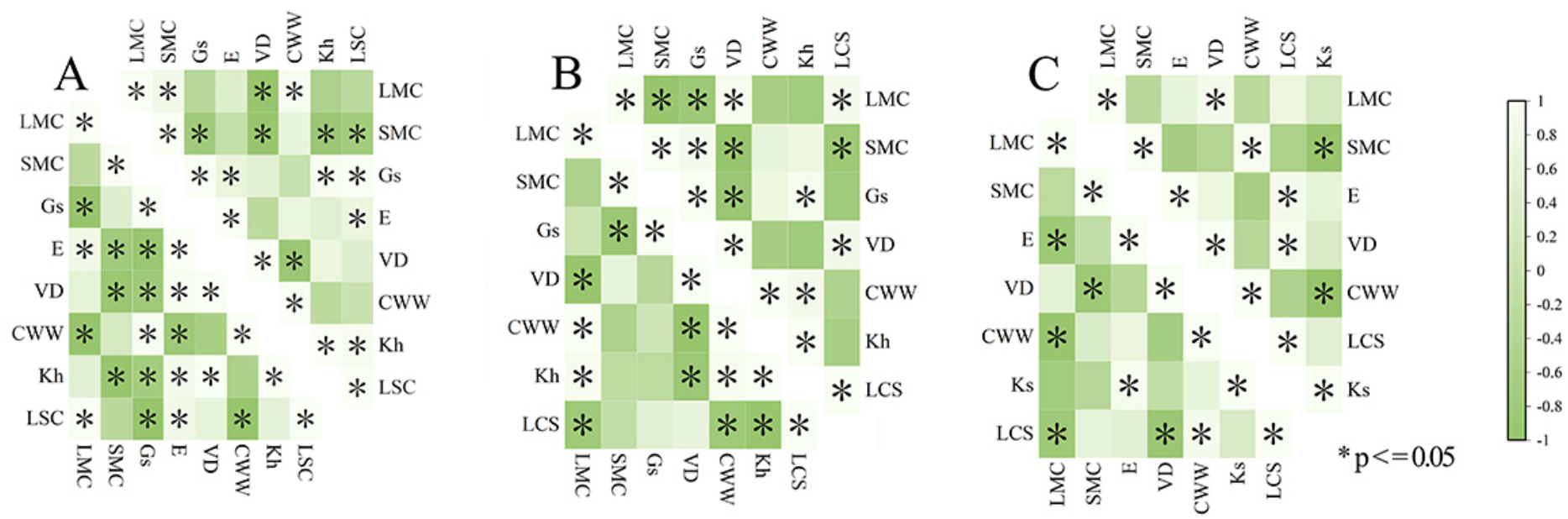

Figure 7

Correlation heat map in the upper right is after stress and the lower left is the blank group (LMC, leaf metal content; SMC, stem metal content; GS, stomatal conductance; Tr, transpiration rate; Vd, vessel diameter; Cwt, cell wall thickness): A: Kochia scoparia, B: Chenopodium glaucum, and C: Atriplex centralasiatica.

\section{Supplementary Files}

This is a list of supplementary files associated with this preprint. Click to download.

- AppendixFig.1.png 